\title{
Determination of Hydraulic Properties of a Large Self-Propped Hydraulic Fracture in the Geothermal Research Borehole Horstberg Z1 in the Northwest German Basin
}

\author{
Reinhard Jung $\mathbb{D}^{1},{ }^{1}$ Alireza Hassanzadegan, ${ }^{2}$ and Torsten Tischner ${ }^{2}$ \\ ${ }^{1}$ JUNG-GEOTHERM UG, Isernhagen 30916, Germany \\ ${ }^{2}$ Federal Institute for Geosciences and Natural Resources (BGR), Hanover 30655, Germany \\ Correspondence should be addressed to Reinhard Jung; jung.geotherm@gmail.com
}

Received 14 March 2019; Revised 14 July 2019; Accepted 13 August 2019; Published 5 November 2019

Guest Editor: Francesco Parisio

Copyright (C) 2019 Reinhard Jung et al. This is an open access article distributed under the Creative Commons Attribution License, which permits unrestricted use, distribution, and reproduction in any medium, provided the original work is properly cited.

\begin{abstract}
The pressure records of an interference test on a huge hydraulic fracture in a layered sedimentary rock formation of the Northwest German Basin were analysed in order to determine fracture transmissivity and fracture storage coefficient. The fracture had been created by injecting some $20,000 \mathrm{~m}^{3}$ of freshwater at $3800 \mathrm{~m}$ depth in borehole Horstberg Z1 of the geothermal research project GeneSys. Its main purpose is to study the hydraulic properties and mechanical behaviour of artificial fractures kept open by the so called self-propping effect which results from the misfit of the opposite fracture surfaces being sheared during fracture propagation. A diagnosis of the pressure records of the interference test showed that the flow geometry is parallel (vertical linear fracture flow) rather than radial or bilinear. This is explained by assuming a highly conductive flow channel within the fracture resulting from a turn of tensile to mixed-mode fracture propagation. Based on this observation an analytical 1D-model was developed that describes transient fluid-flow in a vertical fracture that is imbedded in impermeable rock and is vertically confined by permeable rock layers. This model was verified by a corresponding 1D-numerical model and was then used to fit the observed pressure records of the constant rate interference test. The fitting procedure yielded a transmissivity of the self-propped fracture in claystone that is more than ten times lower than the transmissivity of self-propped fractures in granite as observed in HDR/EGS systems (Hot-Dry-Rock/Enhanced Geothermal Systems). At the same time it is more than ten times higher than the transmissivity of propped fractures in shale gas reservoirs. The injectivity index of the studied fracture resulting from transmissivity and the high length to height ratio of the fracture enables to circulate water or brine through the fracture at flow rates up to about $0.005 \mathrm{~m}^{3} / \mathrm{s}$. For the given temperature of about $150^{\circ} \mathrm{C}$ this would satisfy the heat demand of small to medium size building complexes. Higher flow rates and heat production could be achieved with multiple fractures of this kind. The results obtained in borehole Horstberg Z1 are promising but more in-situ experiments in various rock formations and different stress regimes are necessary to generalize the results.
\end{abstract}

\section{Introduction}

In 2001 the Federal Institute of Geosciences and Natural Resources (BGR) in Hanover started the geothermal research project GeneSys (Generated Geothermal Energy Systems). The aim of the project is to investigate whether and how geothermal energy for district heating can be accessed from Triassic rock formations, particularly from the Middle Bunter of the Northwest German Basin [1]. The Middle Bunter mainly consists of clay- and siltstone with layers of middle to coarse grained sandstone. The low to moderate transmissivity of these sandstone layers prohibits conventional assessment of geothermal fluids on most locations.

The favoured concept for small to medium size heat consumers $\left(1-5 \mathrm{MW}_{\mathrm{th}}\right)$ developed and tested in the GeneSysProject is a one-hole concept. It envisages to create a large vertical hydraulic fracture starting from the bottom part of a deviated borehole and extending upward to a sandstone layer with moderate permeability. For heat extraction cold water is injected trough a thermally insulated tubing running from the top of the well to a packer set on top of the fracinterval. The water heats-up in the fracture and is produced 


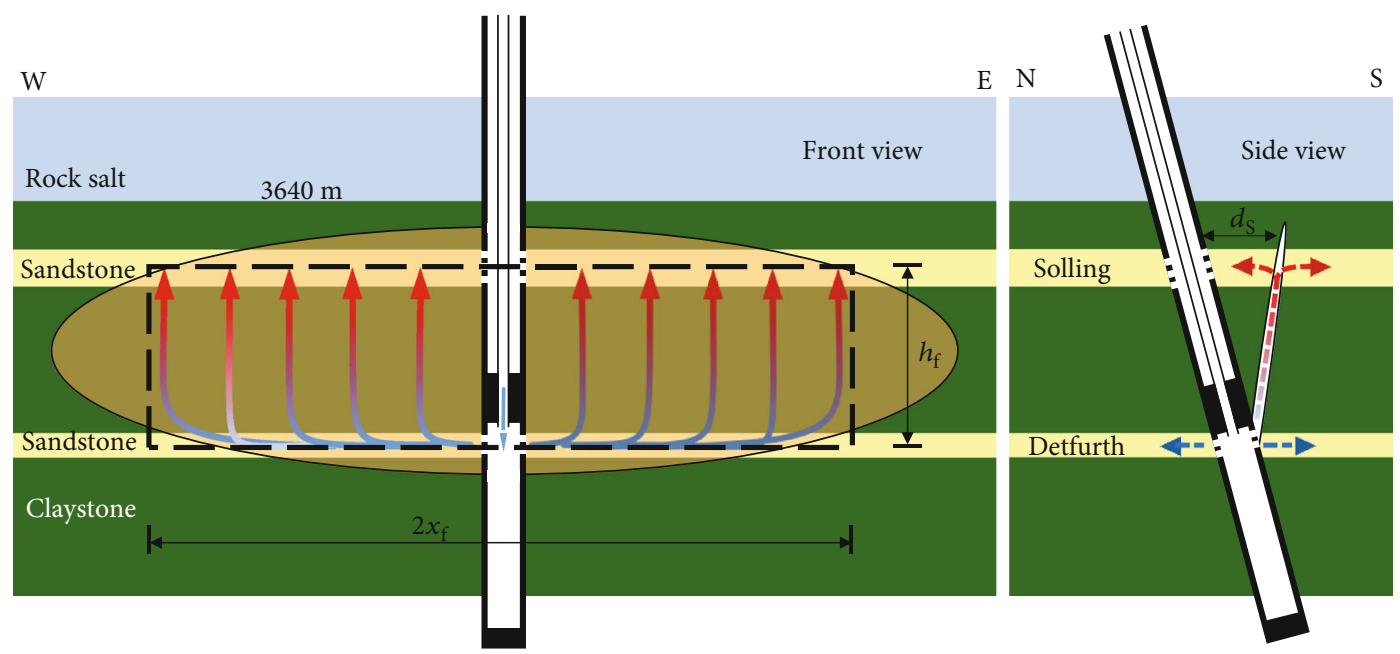

Figure 1: Unscaled scheme of the fracture and the well-completion at the HDR/EGS - test site GeneSys-Horstberg. Dashed rectangle: simplified fracture geometry for the $1 \mathrm{D}$-model, $2 \mathrm{x}_{\mathrm{f}}$ : fracture length, $\mathrm{h}_{\mathrm{f}}$ : fracture height, $\mathrm{d}_{\mathrm{s}}$ : horizontal distance between borehole and fracture in the Solling.

from a perforated casing section in the upper sandstone layer via the annulus between tubing and casing. In order to maintain heat production for about 30 years a fracture with a heatexchanging area of several hundred thousand square-meters is required.

Fractures of this size are by more than a factor of 100 bigger than propped hydraulic fractures in conventional oil- and gas-reservoirs and are about ten times larger than the so called slickwater-fracs in unconventional shale gas reservoirs. Due to the enormous size of the envisaged fractures the use of proppants was excluded from the onset since it seemed technically impossible to effectively transport proppants over such large distances within the fractures. Furthermore the costs would be very high. Instead large volumes of freshwater with no additives and proppants were used for the frac-tests. In doing so one has to rely solely on the so called selfpropping effect. Self-propping occurs when the two opposite fracture surfaces are laterally displaced during the fracprocess. This results in a misfit of the rough and uneven fracture surfaces so that the fracture does not close completely during post-frac pressure depletion. The self-propping mechanism proved to be very effective in EGS/HDR-projects where fractures with a size of several square-kilometres were created in granite by injecting some $10,000 \mathrm{~m}^{3}$ of freshwater or brine. Fracture transmissivities up to several darcy.m allowed circulation flow rates of up to $0.03 \mathrm{~m}^{3} / \mathrm{s}$ on various EGS/HDR test sites [2, 3].

The success of the EGS/HDR-projects motivated BGR, which was engaged in EGS/HDR-projects from the beginning, to apply the proppant-free waterfrac-technique also in low permeable sedimentary rock of the Northwest German Basin were the crystalline basement cannot be reached by drilling. For this mean several hydraulic fracturing operations and a series of post-frac experiments were performed in 2003 and 2004 in the abandoned gas well Horstberg Z1 located about $60 \mathrm{~km}$ North-East of Hanover [4].

One of the major questions of these tests was to find out whether the transmissivity of self-propped fractures in sedi- mentary rock would be sufficient for geothermal applications. However, the invaluable data set of the Horstberg experiments had not been evaluated with this respect mainly for the lack of a proper model but also because the activities in the GeneSys project shifted to a new geothermal site on the campus of BGR in Hanover.

The applicability of self-propped fractures in sedimentary rock was also a question in the European shale gas project "FracRisk" [5]. Here it was addressed by a literature survey for transmissivity data of self-propped fractures in shale gas reservoirs. Obviously, no serious attempts were made by the oil and gas industry to test and apply a proppant-free frac-technique in shale gas wells. It may be for this reason that no field data for the transmissivity of self-propped shale gas fractures were found.

In order to get at least one data point relevant for both applications the GeneSys-group and the FracRisk project cooperated in evaluating the data of a pressure interference test on a large self-propped fracture in borehole Horstberg Z1. This included the following subtasks: processing and diagnosis of the pressure records, establishment of a conceptual model, derivation of an analytical solution for transient fluid flow in this model, implementation of the solution in a computer-program, verification of this program by a corresponding 1D-numerical model, determining transmissivity and storage coefficient by fitting the pressure records of the test with the analytical solution, sensitivity studies.

The main reasons for the analytical treatment of the problem was to gain a thorough physical understanding of the complex hydraulic interaction between the fracture and the two sandstone layers confining the fracture at its top and its bottom.

\section{Test-Conditions and Test-Configuration}

The interference test was performed in borehole Horstberg $\mathrm{Z} 1$ in the upper $300 \mathrm{~m}$ of the Middle Bunter (see Figure 1). This part of the Middle Bunter consists mainly of claystone 
TABle 1: Parameter-values of the Solling and Detfurth sandstone layers. Central depth means depth of the middle of the sandstone layer. Depth means measured depth in the borehole. It differs by less than $1 \%$ from true vertical depth.

\begin{tabular}{lcccc}
\hline Parameter & Unit & Solling & Detfurth & Reference \\
\hline Central depth & $\mathrm{m}$ & 3660 & 3785 & {$[7]$} \\
Thickness & $\mathrm{m}$ & 15 & 5 & {$[7]$} \\
Porosity & $\%$ & 11 & 8.5 & {$[7]$} \\
Permeability & $\mathrm{m}^{2}$ & $2 \cdot 10^{-16}$ & $3 \cdot 10^{-15}$ & {$[8]$} \\
Temperature & ${ }^{\circ} \mathrm{C}$ & 144 & 148 & {$[8]$} \\
Pore pressure & $\mathrm{Bar}$ & 584 & 597 & {$[8]$} \\
Vertical stress & $\mathrm{Bar}$ & 860 & 890 & {$[8]$} \\
Minimum horizontal stress & $\mathrm{Bar}$ & 650 & $<680$ & {$[8,9]$} \\
Effective min. Hor. Stress & $\mathrm{Bar}$ & 66 & $<83$ & After [8] \\
\hline
\end{tabular}

and is topped by a thick rock salt layer of the Upper Bunter at a depth of $3640 \mathrm{~m}$. Two horizontal sandstone layers with noticeable permeability and porosity, the Solling and the Detfurth intersect the borehole at a vertical distance of $125 \mathrm{~m}$.

The main parameter values of these layers are given in Table 1. The high pore pressure measured in the Solling and the Detfurth are not uncommon in the Bunter of the Northern German Basin. It corresponds with a static wellhead pressure of 230 bar when the borehole is filled with freshwater. Due to this high pore pressure the effective minimum horizontal stress is quite low (Table 1). Magnitude and orientation of the maximum horizontal stress are unknown. In the Bunter of the Northern German Basin they vary significantly on a local scale due to the presence of salt domes and pillows [6].

Borehole Horstberg Z1 had originally been drilled and completed for gas exploration and exploitation in the Permean Rotliegend-Formation. Its total depth is $4918 \mathrm{~m}$. Since gas production was uneconomical the lower part of the well was isolated by filling it with cement and setting a bridge plug in the bottom part of the Lower Bunter at $4120 \mathrm{~m}$ depth. The remaining part of the well is completed with a 7"-casing which is cemented up to a depth of $2035 \mathrm{~m}$. The well is almost vertical down to a depth of $2000 \mathrm{~m}$. Here it starts to deviate with increasing angle to the south. In the Middle Bunter, it deviates about $12^{\circ}$ from vertical.

The object of our study, a huge self-propped hydraulic fracture was created by injecting $20,000 \mathrm{~m}^{3}$ of freshwater in a perforated section of the Detfurth [10]. Monitoring of fracture growth by various geophysical methods applied at and near the surface (induced seismicity, tilt-meter, and selfpotential) delivered no information on fracture size and orientation. However, Tischner \& Hetthaus [8] (p.42) determined a fracture size of more than $200,000 \mathrm{~m}^{2}$ from the storage capacitance of the inflated fracture. Temperature logs recorded in the borehole before and after the frac-test show that the fracture is oblique to the borehole axis. Furthermore they indicate that its bottom is $60 \mathrm{~m}$ below the Detfurth and that its top is on the top of the Solling some $125 \mathrm{~m}$ above the Detfurth [8] (p. 43).

The circulation loop was completed by perforating the cemented casing in the Solling and by setting a packer some meters above the Detfurth. A 3.5" tubing runs from the packer up to the surface. This arrangement allows to inject water via the tubing into the Detfurth and fracture and to produce the heated-up water via the annulus from the Solling or vice versa (Figure 1).

For the pressure interference test the annulus was shut-in while freshwater was injected at constant flow rate through the tubing into the Detfurth/fracture intersection. Note that the pressure measured in the annulus (Solling) is not identical with the pressure at the Solling-fracture intersection since this intersection has a certain distance $\mathrm{d}_{\mathrm{s}}$ from the borehole (see Figure 1). For a vertical fracture this distance could be up to $25 \mathrm{~m}$ depending on the orientation of the fracture. The temperature logs indicate that the distance is probably less than $10 \mathrm{~m}$.

\section{Data Analysis and Development of an Analytical 1D-Model}

3.1. Correction of the Pressure Data. Since both the tubing and annulus pressures were monitored at the wellhead, they had to be corrected for frictional pressure losses in the tubing and for the continuous density increase of the liquid column in the tubing and annulus caused by the injection of water at ambient temperature. In addition the heavy oscillations of the wellhead pressures induced by the injection pump were smoothed by taking running averages. The corrected records of the pressure increase at reservoir depth are called Detfurth and Solling pressure, respectively, in the following chapters.

3.2. Diagnosis of the Data. The Detfurth pressure shows an almost perfect square root of time behaviour over the entire length of the test (see Figure 2). The Solling pressure responds with a delay of a few hours and increases by about 0.7 bars until the end of the test.

The square root of time behaviour of the injection pressure is characteristic for formation or fracture linear flow i.e. parallel flow from a fracture into the rock matrix or parallel flow from a line into a fracture, respectively.

3.3. Development of a Conceptual Model. The moderate quality of the pressure data, the plain characteristic of the Detfurth pressure record, and the relatively short duration of the test are asking for a simple conceptual model. For this reason models comprising e.g. poro-elastic and thermoelastic effects in the fracture and rock matrix [11-13] as well as pressure dependent transmissivity and storage coefficient of the fracture were excluded. However the two simplest models to explain the square root of time characteristic, an axial fracture of finite transmissivity in an impermeable matrix (fracture linear flow), or a fracture with infinite transmissivity in a permeable rock (formation linear flow) had to be discarded for various reasons.

After considering several other options we arrived at a model combining both kinds of linear flow (see Figure 3). This model assumes that the stripe of the hydraulic fracture in the Detfurth has an infinitely high transmissivity [8] (p. 51). During injection this flow channel acts as starting line for vertical linear flow in the fracture and at the same 


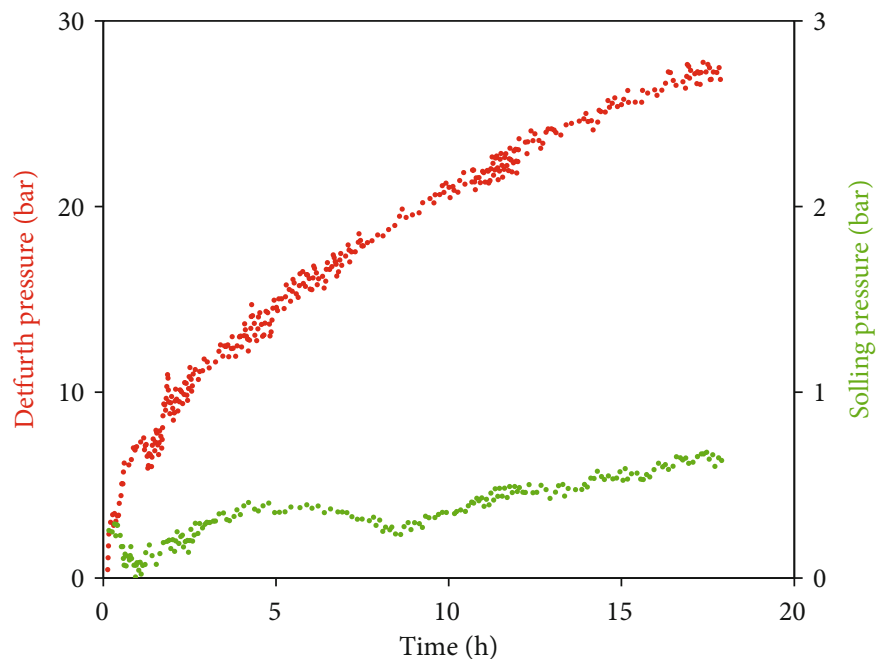

(a)

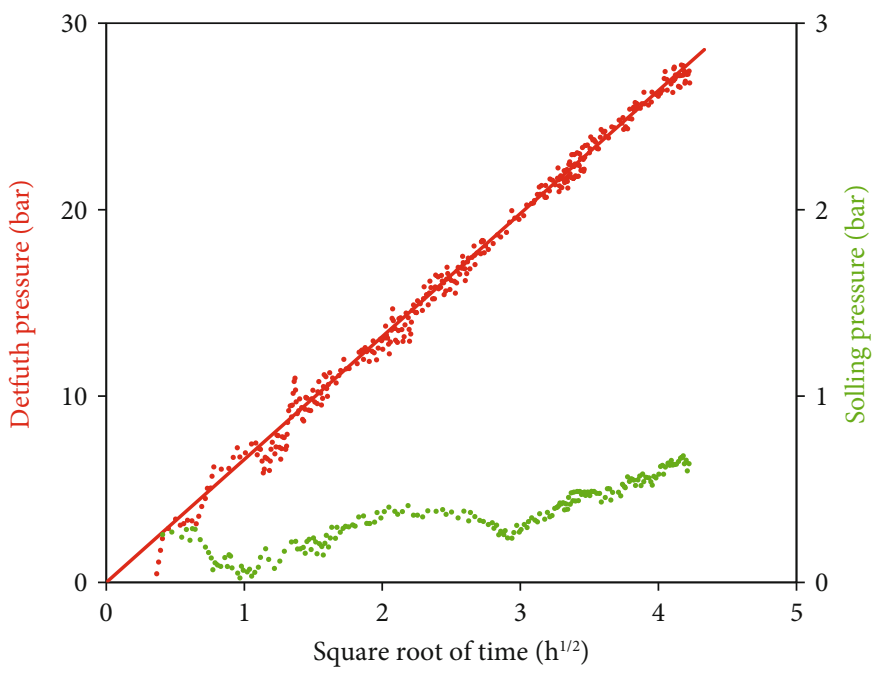

(b)

Figure 2: Processed surface pressure records of the Detfurth (red) and the Solling sandstone (green) vs. elapsed time (left) and square root of elapsed time (right), red straight line: trend line.

time as starting plane for horizontal formation linear flow in the Detfurth. Since the fracture extends up to the top of the Solling, there is also formation linear flow in the Solling.

The 2D-conceptual model was further simplified by transforming it into a $1 \mathrm{D}$-model as illustrated in Figure 4. This is justified as the claystone surrounding the fracture and the two sandstone layers are considered as impermeable.

In the 1D-model the two sandstone layers (Detfurth and Solling) are represented by layers of infinite extent (see Figure 4). They are separated by the fracture of height $\mathrm{h}_{\mathrm{f}}$. Fluid is injected at constant flow rate into a slit of infinite conductivity between Detfurth and fracture. For this configuration the Detfurth and the fracture are connected in parallel, whereas fracture and Solling are connected in line. Since in the real case fluid is injected to both sides of the vertical fracture into the horizontal sandstone layers the transmissivity and storage coefficient of the Detfurth and Solling have to be multiplied by a factor of 2 . By using the parameters trans- missivity and storage coefficient instead of permeability and specific storage coefficient one has not to worry about the different thickness of the sandstone layers and the fracture of the real case.

3.4. Analytical Treatment of the 1D-Model. Each of the two wings the of the $1 \mathrm{D}$-model, the Detfurth on the left side and the fracture and Solling on the right side can be treated by using well-known solutions of corresponding heat conduction problems when the two wings do not interact. Replacing the heat conduction parameters by the corresponding hydraulic parameters the solutions for constant flow rate into each wing of the $1 \mathrm{D}$-model is given by Equations (1), (2) and (3).

$$
p_{D}^{*}(z, t)=\frac{2 Q \sqrt{t}}{2 x_{f} \sqrt{2 S_{D} \cdot 2 T_{D} / \mu}} \cdot \operatorname{ierf} c\left(\frac{|z|}{2 \sqrt{D_{\mathrm{D}} t}}\right)
$$




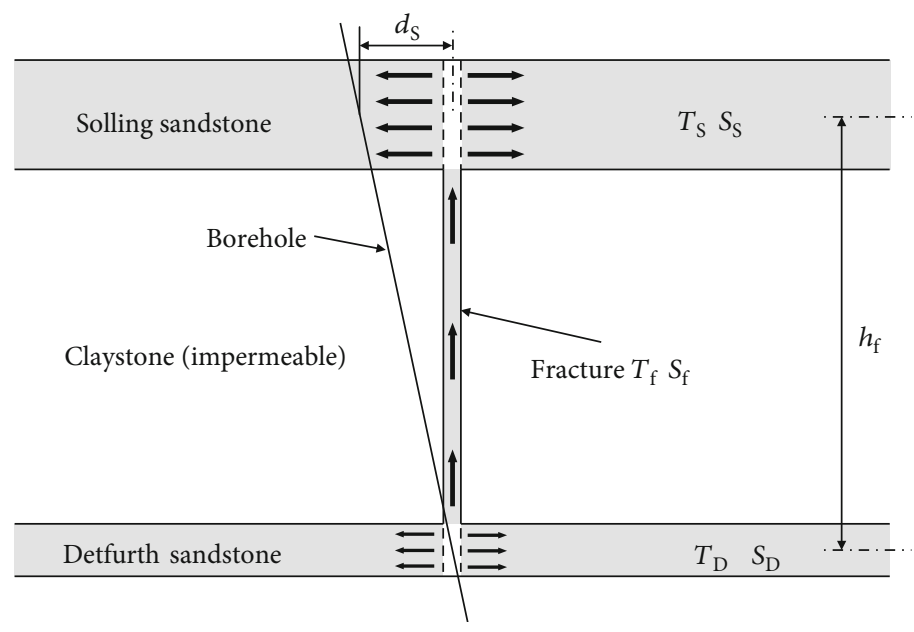

Figure 3: Conceptual model for the test evaluation. White areas in the Detfurth and Solling: flow channels with infinitely high hydraulic conductivity. Black arrows illustrate fracture-linear flow in the fracture and formation linear flow in the Detfurth and Solling. $T_{D}, S_{D}, T_{S}$, $\mathrm{S}_{\mathrm{S}}, \mathrm{T}_{\mathrm{f}}, \mathrm{S}_{\mathrm{f}}$ : transmissivity and storage coefficient of the Detfurth, Solling and fracture, respectively.

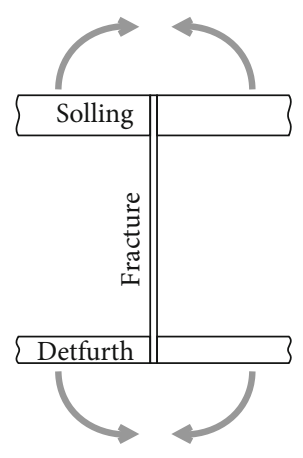

(a)

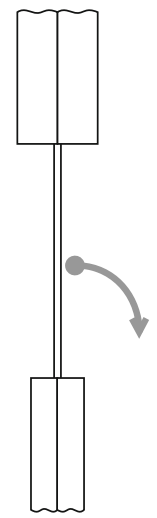

(b)

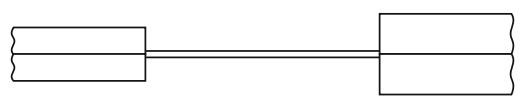

(c)

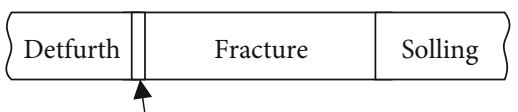

Highly conductive flow channel

(d)
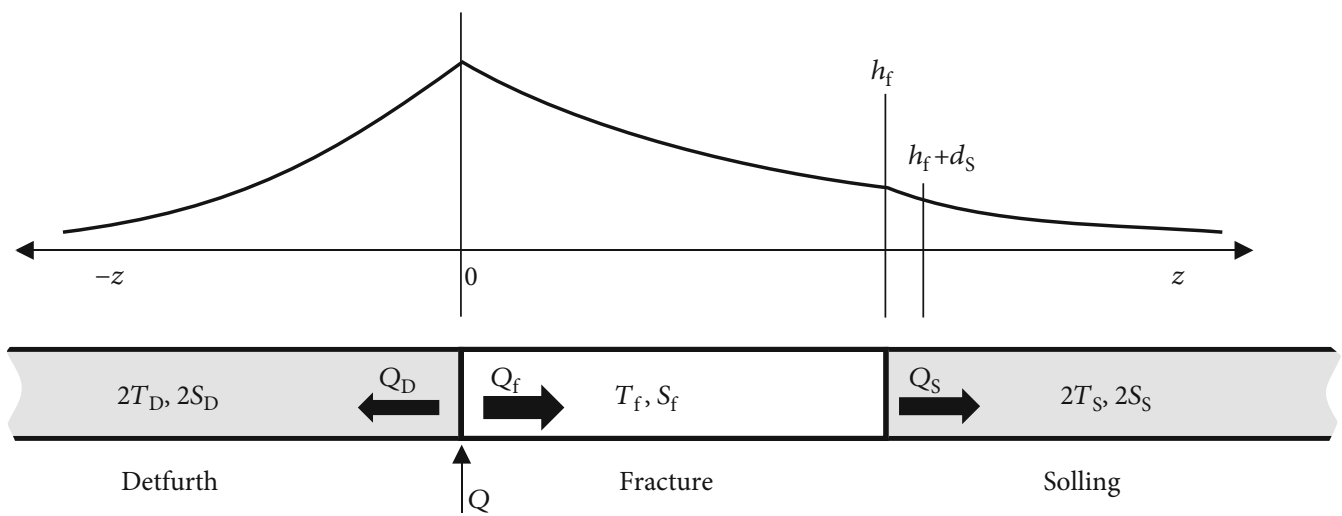

(e)

Figure 4: Top: Steps for transforming the conceptual model of Figure 3 into a 1D-model. Bottom: Scheme of the 1D-model. Q, $Q_{D}, Q_{f}, Q_{S}$ : total flow, flow into the Detfurth, the fracture, and the Solling, respectively. $T_{D}, T_{f}, T_{S}, S_{D}, S_{f}, S_{S}$ : transmissivity and storage coefficient of the Detfurth, the fracture, and the Solling, respectively. Graph: scheme of the expected pressure profile, $h_{\mathrm{f}}$ : fracture height, $d_{\mathrm{s}}$ : horizontal distance between fracture and perforation in the Solling (see Figure 3). 


$$
\begin{aligned}
p_{f c}^{*}(z, t)= & \frac{2 Q \sqrt{t}}{2 x_{f} \sqrt{S_{f} \cdot T_{f} / \mu}} \sum_{n=0}^{\infty}\left(-\alpha_{f S}\right)^{n}\left[\operatorname{ierfc}\left(\frac{2 n h_{f}+z}{2 \sqrt{D_{f} t}}\right)\right. \\
& \left.+\left(-\alpha_{f S}\right) \cdot \operatorname{ierfc}\left(\frac{2(n+1) h_{f}-z}{2 \sqrt{D_{f} t}}\right)\right]
\end{aligned}
$$

$$
\begin{aligned}
p_{S c}^{*}(z, t)= & \frac{2 Q \sqrt{t}}{2 x_{f} \sqrt{S_{f} \cdot T_{f} / \mu}} \cdot\left(1-\alpha_{f S}\right) \cdot \sum_{n=0}^{\infty}\left(-\alpha_{f S}\right)^{n} \operatorname{ierfc} \\
& \cdot\left(\frac{(2 n+1) h_{f}}{2 \sqrt{D_{f} t}}+\frac{z-h_{f}}{2 \sqrt{D_{S} t}}\right)
\end{aligned}
$$

With:

$$
\begin{aligned}
& p_{D}^{*}, p_{f c}^{*}, p_{S c}^{*}[P a] \text { Pressure in the Detf urth, fracture, Solling resp. } \\
& S_{D}, S_{f}, S_{S}\left[\frac{m}{P a}\right] \text { Storage coefficient of Detfurth, fracture, Solling resp. } \\
& T_{D}, T_{f}, T_{f}\left[m^{3}\right] \text { Transmissivity of Detfurth, fracture, Solling resp. } \\
& D_{D}, D_{f}, D_{f}\left[\frac{m^{2}}{s}\right] \text { Hydr.diffusivity of Detfurth, fracture, Solling resp. } \\
& Q\left[\mathrm{~m}^{3} / s\right] \text { Injection flow rate } \\
& \mu[P a \cdot s] \text { Viscosity of the fluid } \\
& 2 x_{f}[m] \text { Fracture length } \\
& h_{f}[m] \text { Fracture height }
\end{aligned}
$$

The storage coefficients $S$ and transmissivities $T$ of these equations are related to the storage coefficients $S^{*}$ and transmissivities $\mathrm{T}^{*}$ used in hydrogeology in the following way:

$$
\begin{gathered}
S^{*}[-]=\rho g \cdot S \\
T^{*}\left[m^{2} / s\right]=\frac{\rho g}{\mu} \cdot T
\end{gathered}
$$

Inserting $\rho \approx 950 \mathrm{~kg} / \mathrm{m}^{3}$ (density of water at reservoir conditions), $\mu \approx 3 \cdot 10^{-4} \mathrm{~Pa} \cdot \mathrm{s}$ (viscosity of water at reservoir conditions) and $\mathrm{g}=9.81 \mathrm{~m} / \mathrm{s}^{2}$ (acceleration of gravity) in Equations (5) and (6) we get:

$$
\begin{gathered}
S^{*}[-] \cong 9.3 \cdot 10^{3} \cdot S\left[\frac{m}{P a}\right] \\
T^{*}\left[\mathrm{~m}^{2} / \mathrm{s}\right] \cong 3.1 \cdot 10^{7} \frac{1}{\mathrm{~m} \cdot \mathrm{s}} \cdot T\left[\mathrm{~m}^{3}\right]
\end{gathered}
$$

The terms - $\alpha_{\mathrm{fs}}$ and - (1- $\alpha_{\mathrm{fs}}$ ) of Equations (2) and (3) may be called "reflection" and "transmission coefficient", respectively. They are given by:

$$
\begin{gathered}
-\alpha_{f S}=-\frac{\sigma_{f S}-1}{\sigma_{f S}+1} \\
-\left(1-\alpha_{f S}\right)=-\left(1-\frac{\sigma_{f S}-1}{\sigma_{f S}+1}\right)
\end{gathered}
$$

With:

$$
\sigma_{f S}=\sqrt{\frac{2 T_{S} \cdot 2 S_{S}}{T_{f} \cdot S_{f}}}
$$

The integral of the complementary error function ierfc $(\mathrm{x})$ is defined as:

$$
\operatorname{ierfc}(x)=\frac{1}{\sqrt{\pi}} e^{-x 2}-x \cdot \operatorname{erfc}(x)
$$

With:

$$
\operatorname{ierfc}(0)=\frac{1}{\sqrt{\pi}}
$$

Equation (1) is the constant flow rate solution for the Defurth that corresponds to the heat conduction solution for constant heat flux into the semi-infinite half space given by Carslaw \& Jaeger [14] (p.75). Equation (2) and (3) are the constant flow rate solutions for the right wing of the 1D-model where the fracture and the Solling are connected in series. They correspond to the heat conduction solutions for the composite solid with two media connected in series for constant heat flux given by Carslaw \& Jaeger [14] (p.322).

The problem is to combine the solutions of the left and the right wing of the $1 \mathrm{D}$-model where one of the wings is composed of two elements connected in line. 
Diaz [15] treated a corresponding heat conduction problem. However he treated the case with constant temperature at the interface between the two wings. So his solution does not apply.

Carslaw \& Jaeger [14] (p.88) give a solution for the case of an infinite composite solid with heat supplied at constant rate at the interface between (infinite) medium 1 and (infinite) medium 2. By analogy we established the following solutions for our problem (Equations (12), (13) and (14)):

$$
\begin{aligned}
& p_{D}(z, t)=\lambda_{0} \cdot p_{D}^{*}(z, t) \\
& p_{f c}(z, t)=\left(1-\lambda_{0}\right) \cdot p_{f c}^{*}(z, t) \\
& p_{S c}(z, t)=\left(1-\lambda_{0}\right) \cdot p_{S c}^{*}(z, t)
\end{aligned}
$$

Equations (12), (13) and (14) are the solutions for the Detfurth, the fracture, and the Solling, respectively.

The coefficients $\lambda_{0}$ and $\left(1-\lambda_{0}\right)$ are the flow rate fractions of the Detfurth and the fracture, respectively, when the two wings are connected in parallel. They are determined by inserting the one-wing solutions of Equations (1) and (2) into Equations (12) and (13) and setting the latter equal for $\mathrm{z}=0$. This should be done for a time $t$ small enough that all terms of Equation (2) with $\mathrm{n}>0$ including the second term in the bracket of Equation (2) for $n=0$ can be neglected at $z=0$. In this case we get:

$$
\begin{aligned}
p_{D}(0, t) & =\frac{2 \lambda_{0} Q \sqrt{t}}{2 x_{f} \sqrt{2 S_{D} \cdot 2 T_{D} / \mu}} \cdot \frac{1}{\sqrt{\pi}} \\
& =p_{f}(0, t)=\frac{2\left(1-\lambda_{0}\right) Q \sqrt{t}}{2 x_{f} \sqrt{S_{f} \cdot T_{f} / \mu}} \cdot \frac{1}{\sqrt{\pi}}
\end{aligned}
$$

Solving Equation (15) for $\lambda_{0}$ we get:

$$
\begin{aligned}
\lambda_{0} & =\frac{\sqrt{2 S_{D} \cdot 2 T_{D}}}{\sqrt{S_{f} \cdot T_{f}}+\sqrt{2 S_{D} \cdot 2 T_{D}}} \\
\text { and } 1-\lambda_{0} & =\frac{\sqrt{S_{f} \cdot T_{f}}}{\sqrt{S_{f} \cdot T_{f}}+\sqrt{2 S_{D} \cdot 2 T_{D}}}
\end{aligned}
$$

Inserting $\lambda_{0}$ and $1-\lambda_{0}$ in Equation (15) yields:

$$
\begin{aligned}
p_{D}(0, t) & =p_{f}(0, t)=\frac{2 Q \sqrt{t}}{2 x_{f}\left(\sqrt{S_{f} \cdot T_{f} / \mu}+\sqrt{2 S_{D} \cdot 2 T_{D} / \mu}\right)} \cdot \frac{1}{\sqrt{\pi}} \\
& =m \cdot \sqrt{t}
\end{aligned}
$$

(17) is the short-term solution for the pressure at $\mathrm{z}=0$ (Detfurth/fracture boundary). This short-term solution can be applied to our problem as long as the measured Detfurth pressure vs. square root of time plot follows a straight line. When the measured pressure starts to deviate from the straight line the flow fractions of the Detfurth and fracture become time dependent since from now on the effect of the fracture/Solling boundary becomes noticeable at the
Detfurth/fracture interface. Since this did not happen Equations (12), (13) and (14) can be applied for the entire test. Nevertheless we developed also an analytical method for longer times with time dependent flow fractions. The description of the method however is beyond the scope of this article. Both, the short and long term solutions were installed in a spreadsheet program.

3.5. Verification of the Analytical and a Corresponding Numerical Program. For the verification of the analytical program a corresponding numerical 1D-model was developed with the software package COMSOL Multiphysics. In this model the diffusion equation is solved numerically. No-flow boundaries are applied at $\mathrm{z}=-600 \mathrm{~m}$ and $\mathrm{z}=600 \mathrm{~m}$ in the Detfurth and the Solling sandstone, respectively. The permeability and the specific storage coefficient for the fracture, the Detfurth sandstone, and the Solling sandstone were taken such that their product with the uniform thickness of these elements were equal to the transmissivities and storage coefficients used in the analytical model. The results obtained with the analytical and numerical models agreed almost perfectly (see Figure 5).

\section{Results}

4.1. Temporal Evolution of Pressure and Flow Rate. The pressure records of the Detfurth- and Solling-pressure were fitted with the analytical program for two fracture lengths and fixed hydraulic parameter values for the Detfurth and the Solling (Table 2). Since the transmissivity of the Detfurth was not as well constrained as that of the Solling, two limiting values were assumed. Fitting parameters were fracture transmissivity and fracture storage coefficient.

The fit-curve of the Detfurth-pressure for $1000 \mathrm{~m}$ fracture length showed the same perfect square-root of time characteristic as the measured curve over the entire length of the test (see Figure 6). The fit curves for 2000 fracture length had a minor downward trend at the end of the test. One can therefore conclude that the fracture length is smaller than $2000 \mathrm{~m}$.

When comparing the measured and the calculated pressure of the Solling one should keep in mind that the measured pressure signal was very small (below 1 bar) and disturbed by a fluid-density increase resulting from the continuous cooling of the borehole during injection. These were compensated as good as possible but small irregular changes remained during the first half of the test. Neglecting these one can state that the fit quality for the Solling pressure is quite good for $2000 \mathrm{~m}$, but poor for $1000 \mathrm{~m}$ fracture length (see Figure 6). For this reason we can state that the fracture is longer than $1000 \mathrm{~m}$. We can therefore conclude that fracture length is in-between $1000 \mathrm{~m}$ and $2000 \mathrm{~m}$. This agrees well with the fracture size determined by Tischner et al. [8] (p.42).

The graphs of the flow rate for the two fracture lengths differ strongly (see Figure 6). They show that the flow rate of the fracture decreases by a factor of more than 5 when the fracture length is increased from $1000 \mathrm{~m}$ to $2000 \mathrm{~m}$. For $1000 \mathrm{~m}$ fracture length the flow fractions are constant with 


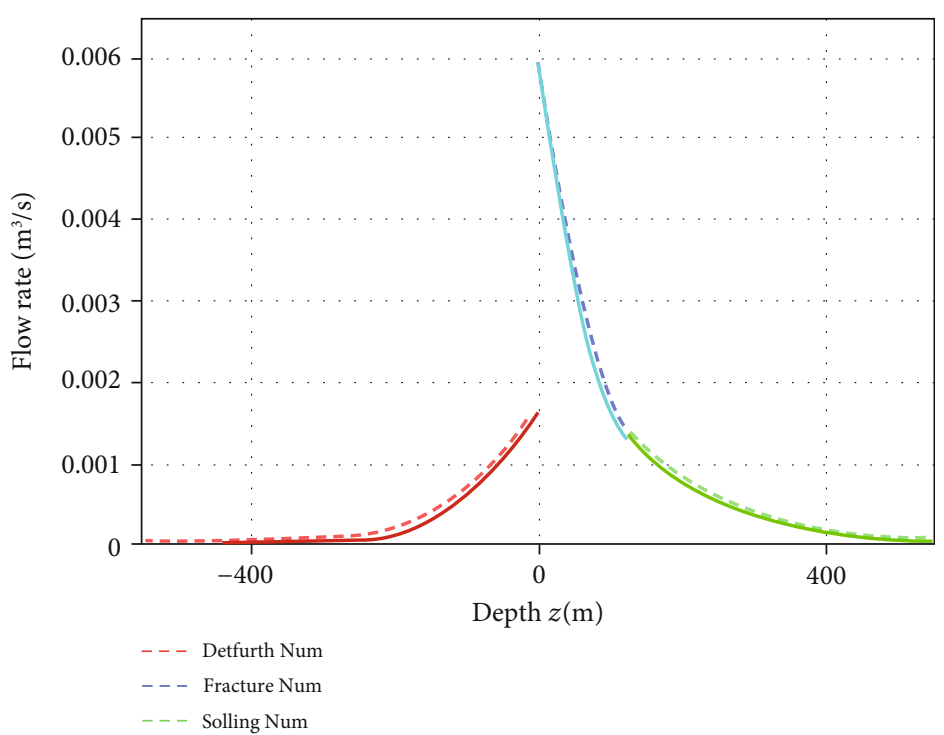

FIgURE 5: Flow rate profiles calculated with the numerical program (dashed lines) and the analytical program (solid lines) after 18 hours of water injection at constant flow rate of $0.0076 \mathrm{~m}^{3} / \mathrm{s}$.

TABle 2: Predetermined parameter-values used for the fitting procedure. Hydraulic parameter values for the Detfurth and Solling, after [8] (pp.50-54).

\begin{tabular}{lccc}
\hline Parameter & Symbol & Value & Unit \\
\hline Fracture length & $2 \mathrm{x}_{\mathrm{f}}$ & $1000 ; 2000$ & $\mathrm{~m}$ \\
Fracture height & $\mathrm{h}_{\mathrm{f}}$ & 125 & $\mathrm{~m}$ \\
Distance fracture-borehole & $\mathrm{d}_{\mathrm{s}}$ & 25 & $\mathrm{~m}$ \\
Viscosity & $\mu$ & $3 \cdot 10^{-4}$ & $\mathrm{~Pa} \cdot \mathrm{s}$ \\
Test duration & $\mathrm{t}_{\mathrm{e}}$ & 18 & $\mathrm{~h}$ \\
Flow rate & $\mathrm{Q}$ & $7.6 \cdot 10^{-3}$ & $\mathrm{~m}^{3} / \mathrm{s}$ \\
Transmissivity Detfurth & $\mathrm{T}_{\mathrm{D}}$ & $1.5 \cdot 10^{-14} ; 9 \cdot 10^{-15}$ & $\mathrm{~m}^{3}$ \\
Transmissivity Solling & $\mathrm{T}_{\mathrm{S}}$ & $3.2 \cdot 10^{-13}$ & $\mathrm{~m}^{3}$ \\
Storage coefficient Detf. & $\mathrm{S}_{\mathrm{D}}$ & $2.5 \cdot 10^{-10}$ & $\mathrm{~m} / \mathrm{pa}$ \\
Storage coefficient Solling & $\mathrm{S}_{\mathrm{S}}$ & $1.5 \cdot 10^{-9}$ & $\mathrm{~m} / \mathrm{pa}$ \\
\hline
\end{tabular}

time. For $2000 \mathrm{~m}$ the Detfurth flow rate decreases slightly while the flow rate into the fracture rises by the same amount. The reason for the upward trend of the fracture flow rate are the much higher transmissivity and storage coefficient of the Solling as compared to the Detfurth.

4.2. Spatial Pressure and Flow Rate Profiles. The pressure profiles for $\mathrm{t}_{\mathrm{e}}=18 \mathrm{~h}$ (see Figure 7 ) show that due to its high transmissivity and storage coefficient the Solling is almost acting as a constant pressure boundary. The flow rate profiles show that the flow through the fracture has not reached steady state conditions even after $18 \mathrm{~h}$ of injection. Fluid storage in the fracture is still consuming a big part of the flow rate entering the fracture at the inlet.

Although the test was relatively short the injection had far reaching effects in the sandstone layers. The distance of influence of about $400 \mathrm{~m}$ in the Detfurth is almost equal for pressure and flow rate and is nearly independent of fracture length. In the Solling the far field effect is strong for the flow rate but hardly noticeable for the pressure. This proofs that the weak pressure response in the Solling is caused to a big part by the comparatively high transmissivity and storage coefficient of the Solling.

The far reaching influence of the injection in the Detfurth and Solling is a warning that the $1 \mathrm{D}$-model might approach the limit of its applicability. This limit is reached when the ratio between distance of influence and fracture length exceeds a certain value because here the transition to an elliptical flow geometry in the two sandstone layers will start to affect the pressure evolution. This was not yet the case since the pressure vs. square root of time plot of the Detfurth was straight until the end of the test.

4.3. Fitting Results. The parameter of highest practical importance is the injectivity index $\mathrm{II}_{\mathrm{f}}$ of the fracture. For quasi steady state conditions in the fracture this parameter is given by the quotient of the flow rate in the fracture and the pressure difference between fracture inlet and outlet. This condition had not been reached for the two cases (see Figure 7). It was therefore calculated by using Equation (18).

$$
I I_{f}=\frac{T_{f}}{\mu} \frac{2 x_{f}}{h_{f}}
$$

With $h_{f}$ : fracture height, $\mu$ : fluid viscosity, and $2 x_{f}$ : fracture length.

The injectivity index was the same for both fracture lengths. This means it is uniquely determined independent of fracture length and can be determined also for cases where the flow conditions in the fracture are far from steady state.

According to Equation (18) fracture transmissivity is invers to fracture length for constant injectivity index $\mathrm{II}_{\mathrm{f}}$. 

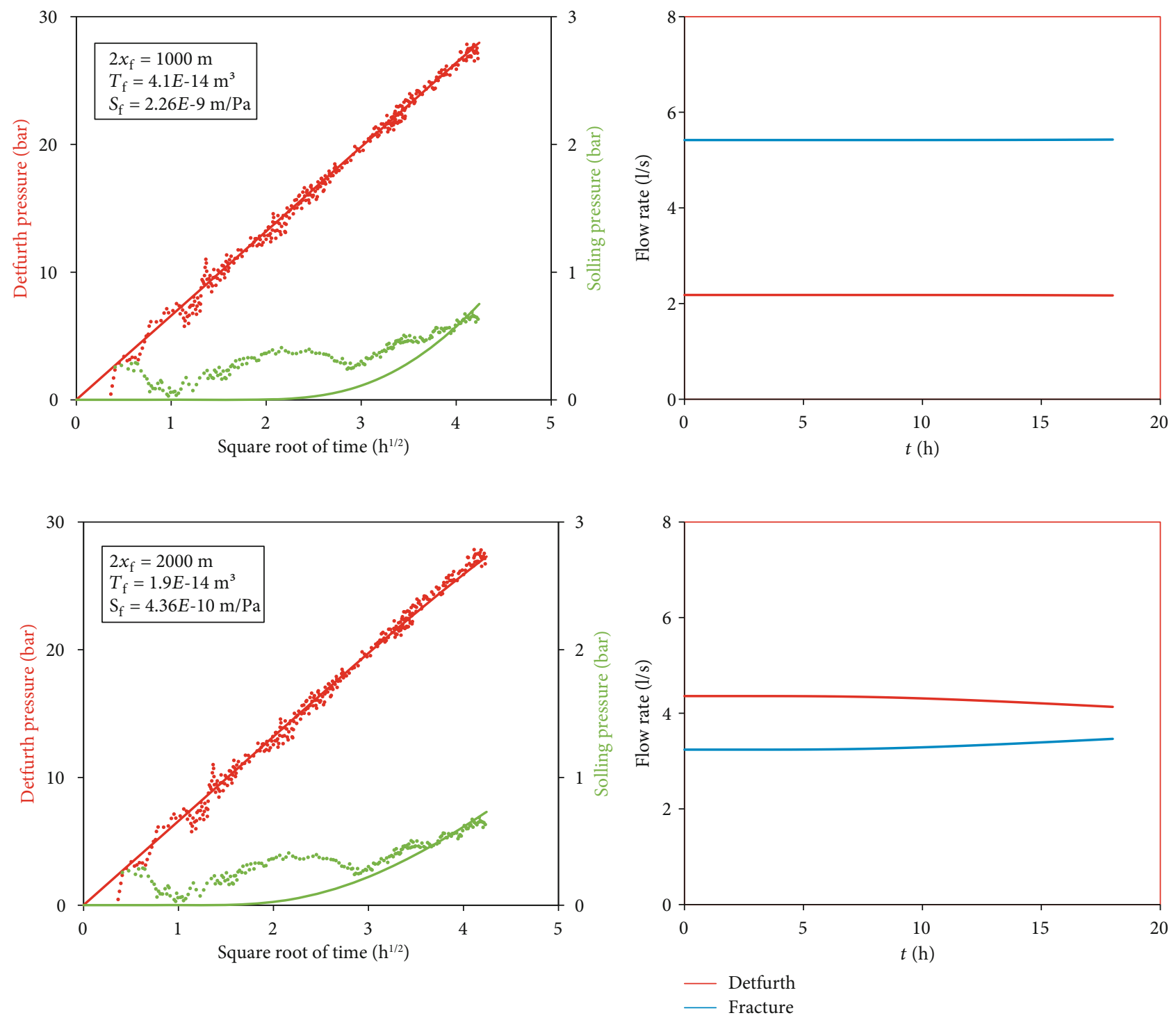

Figure 6: Measured (dotted) and calculated pressure (solid) vs. square root of time of the Detfurth (red) and the Solling (green), for the two limiting fracture lengths $2 \mathrm{x}_{\mathrm{f}}=1000 \mathrm{~m}$ and $2000 \mathrm{~m}$ and Detfurth transmissivity $\mathrm{T}_{\mathrm{D}}=1.5 \cdot 10^{-14} \mathrm{~m}^{3}$. Calculated flow rate records of the Detfurth sandstone (red) and the fracture (blue) for the same parameters as left.

The values of fracture transmissivity determined by the fitting procedure confirm this (Table 3). The fracture storage coefficient $S_{f}$ decreases stronger than linearly with the inverse of fracture length. For this reason fracture diffusivity increases with increasing fracture length despite of the decrease of fracture transmissivity (Table 3). As a consequence the pressure migrates faster in the longer fracture and steady state conditions in the fracture will be approached earlier.

The fracture parameter values obtained with the $1 \mathrm{D}$-model are reasonable except for the fracture storage coefficient. For an un-inflated fracture with only moderate transmissivity the values are amazingly high particular for $1000 \mathrm{~m}$ fracture length. Here they even exceed the storage coefficient of the $15 \mathrm{~m}$ thick Solling sandstone layer. Common fracture models like the "Bed of Nail" model (see Figure 8(a)) can hardly explain this. This is demonstrated by the following estimate. According to the cubic law the aperture $\mathrm{w}_{\mathrm{f}}[\mathrm{m}]$ is given by:

$$
w_{f}: \sqrt[3]{12 T_{f}}
$$

Inserting the fracture transmissivity of $\mathrm{T}_{\mathrm{f}}=4.1 \cdot 10^{-14} \mathrm{~m}^{3}$ for $1000 \mathrm{~m}$ fracture length (see Table 3) the aperture amounts to:

$$
w_{f}=8 \cdot 10^{-5} \mathrm{~m}
$$

For incompressible fluid the fracture storage coefficient is given by:

$$
S_{f}=\frac{\partial w_{f}}{\partial p}
$$



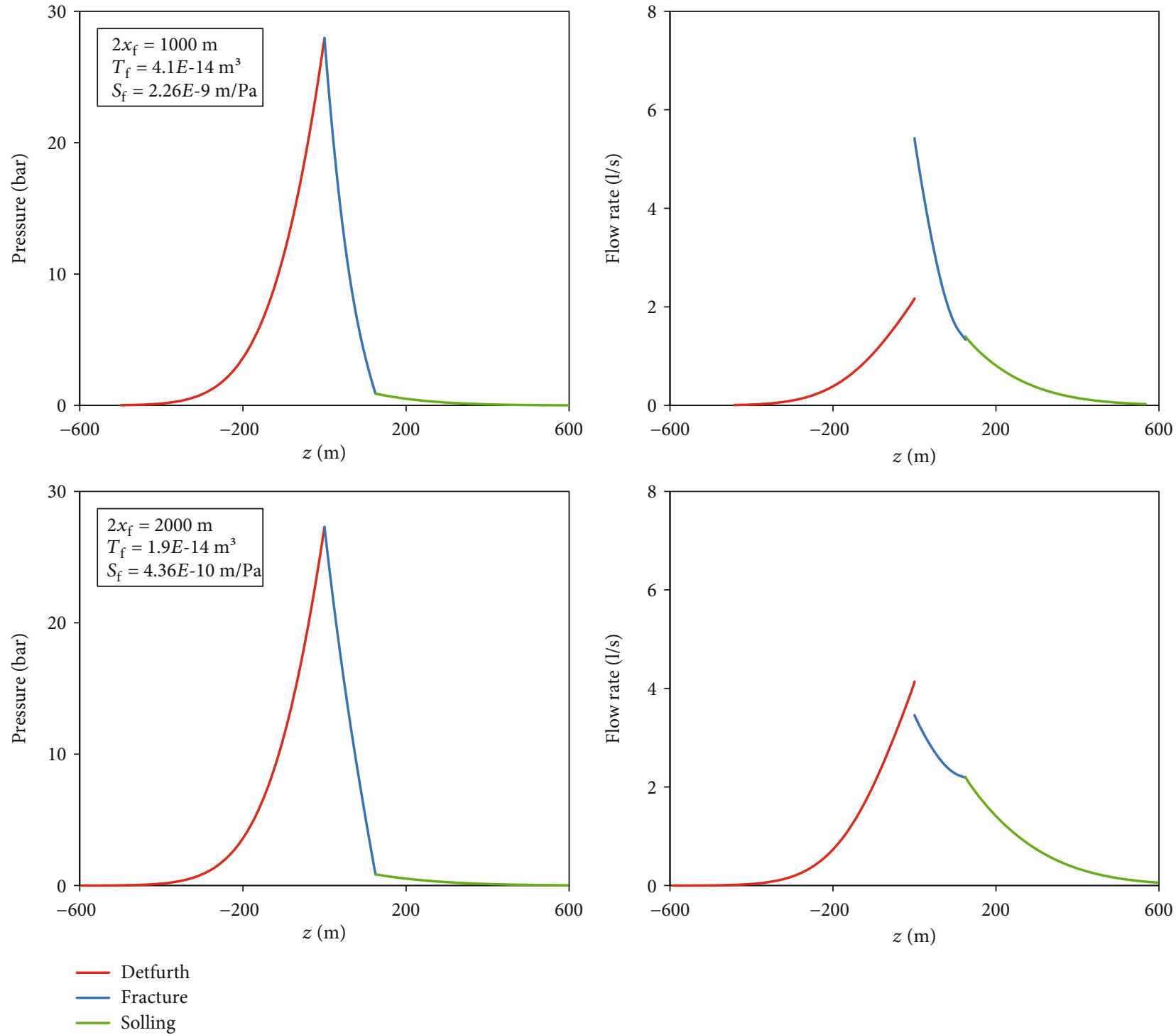

FIgURE 7: Calculated pressure profiles and calculated flow rate profiles in the Detfurth (red), the fracture (blue), and the Solling (green) at the end of the injection period $t_{e}=18 \mathrm{~h}$ for the 2 limiting fracture lengths $2 \mathrm{x}_{\mathrm{f}}$ and $\mathrm{T}_{\mathrm{D}}=1.5 \cdot 10^{-14} \mathrm{~m}^{3}$.

TABLE 3: Values of fracture transmissivity $T_{f}$, storage coefficient $S_{f}$, diffusivity $\mathrm{D}_{\mathrm{f}}$, and injectivity index $\mathrm{II}_{\mathrm{f}}$ determined by the fitting procedure for the two limiting values of fracture lengths $2 \mathrm{x}_{\mathrm{f}}$ and Detfurth transmissivity $\mathrm{T}_{\mathrm{D}}$. Values for different horizontal distances $d_{s}$ between fracture and borehole in the Solling are not included since their effect was minor. $\mathrm{T}_{\mathrm{D}}$ : transmissivity of the Detfurth.

\begin{tabular}{cccccc}
\hline $\mathrm{T}_{\mathrm{D}}\left(\mathrm{m}^{3}\right)$ & $2 \mathrm{x}_{\mathrm{f}}(\mathrm{m})$ & $\mathrm{T}_{\mathrm{f}}\left(\mathrm{m}^{3}\right)$ & $\mathrm{S}_{\mathrm{f}}(\mathrm{m} / \mathrm{pa})$ & $\mathrm{D}_{\mathrm{f}}\left(\mathrm{m}^{2} / \mathrm{s}\right)$ & $\mathrm{II}_{\mathrm{f}}\left(\mathrm{m}^{3} /(\mathrm{pa} \cdot \mathrm{s})\right)$ \\
\hline \multirow{2}{*}{$1.5 \cdot 10^{-14}$} & 1000 & $4.1 \cdot 10^{-14}$ & $2.3 \cdot 10^{-9}$ & 0.059 & $1.1 \cdot 10^{-9}$ \\
& 2000 & $1.9 \cdot 10^{-14}$ & $4.4 \cdot 10^{-10}$ & 0.14 & $1.0 \cdot 10^{-9}$ \\
\hline \multirow{2}{*}{$0.9 \cdot 10^{-14}$} & 1000 & $4.4 \cdot 10^{-14}$ & $2.6 \cdot 10^{-9}$ & 0.056 & $1.2 \cdot 10^{-9}$ \\
& 2000 & $2.2 \cdot 10^{-14}$ & $6.5 \cdot 10^{-10}$ & 0.11 & $1.2 \cdot 10^{-9}$ \\
\hline
\end{tabular}

Inserting the fracture storage coefficient $\mathrm{S}_{\mathrm{f}}=2.3 \cdot 10^{-9} \mathrm{~m} / \mathrm{Pa}$ for the $1000 \mathrm{~m}$ long fracture (Table 3) yields:

$$
\frac{\partial w_{f}}{\partial p}=2.3 \cdot 10^{-9} \frac{m}{P a}=2.3 \cdot 10^{-4} \frac{m}{b a r}
$$

Multiplying this value with the Detfurth pressure $\mathrm{p}_{\mathrm{D}}\left(\mathrm{t}_{\mathrm{e}}\right)=28 \mathrm{bar}$ at the end of the test and adding the initial aperture value (Equation (20)) one gets an aperture of $\mathrm{w}_{\mathrm{f}}$ $\left(\mathrm{t}_{\mathrm{e}}\right)=6.5 \cdot 10^{-3} \mathrm{~m}$ and a transmissivity of $\mathrm{T}_{\mathrm{f}}\left(\mathrm{t}_{\mathrm{e}}\right)=2.3 \cdot 10^{-8} \mathrm{~m}^{3}$. This means that aperture and transmissivity of the fracture near the fracture inlet would increase by a factor of 80 and $5.5 \cdot 10^{5}$, respectively, during the test. This is of course incompatible with our observations. For this reason one needs a fracture model where fracture storage coefficient and transmissivity are not coupled via fracture aperture. 


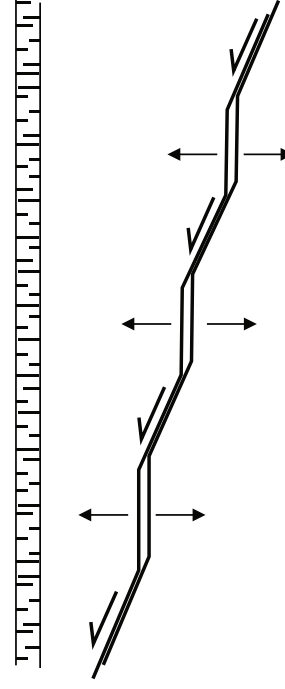

(a)

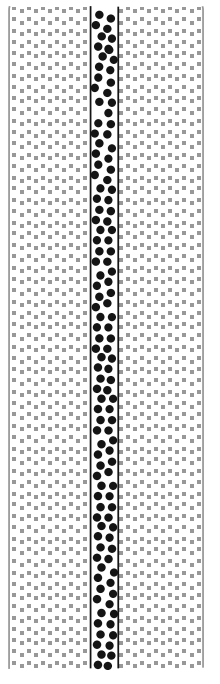

(c)
Figure 8: Scheme of fracture models: (a) Bed of Nail model, the black bars of different length are a proxy for the asperities determining the deformation laws of the fracture. (b) Zig-Zag model comprising tensile and shear fracture elements. (c) Common model for hydraulic fractures in shale gas reservoirs, the propped fracture is surrounded by a zone of intensely fractured and disturbed rock.

The "Zig-Zag" fracture model meets this requirement (see Figure 8(b)). In this model the fracture consists of tensile and shear fracture elements that are connected in line. The former can be considered as capacitors that determine the fracture storage coefficient, whereas the shear fracture elements serve as resistors that determine the fracture transmissivity. In a layered sedimentary rock the multiple change from tensile to shear fracture propagation may be caused by the abrupt change of the minimum horizontal stress at the layers interfaces. This model would also explain the formation of the highly conductive flow channel in the Detfurth that was postulated for our conceptual model. Another fracture model explaining the high storage coefficient is a fracture that is surrounded by a thick zone of intensely broken and disturbed rock (see Figure 8(c)). This model is commonly used in shale gas reservoirs.

4.4. Comparison of the Fracture Transmissivity with Published Data. A number of published transmissivity values of large self-propped hydraulic fractures in granite is available from various HDR/EGS sites [16].

A literature survey performed as part of the FracRisk project revealed that obviously no serious attempts were made in the oil- and gas-industry to investigate the applicability of a proppant-free frac-technology in unconventional oil- \& gas-reservoirs. Early tight-gas articles [17-19] discussed this possibility by referring to the "self-propping effect" but finally state that "In general though, the industry discarded the idea". The term "waterfrac" invented during this time has been misleadingly used since then for slickwater fractests with comparatively low proppant concentrations, which is the standard shale-gas frac-procedure of today. The above statement seems to be valid until today and may explain why no hydraulic conductivity data for un-propped shale gasfractures were found in the vast shale-gas literature.

Even reliable transmissivity data of propped shale gas fractures were sparse. Ehlig-Economides et al. give some data points for the Horn River shale [20], Mayerhofer et al. one for the Barnett shale [21], and Cipolla et al. one for the Utica shale [22]. Some additional data points for propped fractures in the Marcellus shale were determined in the FracRisk project from gas-production records [23].

A comparison of these data with the data point of the studied fracture shows that the transmissivity values of the self-propped fractures in granite are by more than a factor of 10 higher than that of the self-propped fracture in claystone (see Figure 9). This confirms our expectation that the self-propping effect is less effective in the softer fine grained claystone than in the harder coarse-grained granite. The transmissivity value of the studied fracture in turn is by more than a factor of 10 higher than the transmissivity of propped fractures in the various shale gas formations mentioned above (see Figure 9).

\section{Summary and Conclusions}

The pressure records of a constant flow rate interference test was analysed in order to determine flow geometry and hydraulic properties of a large self-propped hydraulic fracture in a layered Triassic rock formation.

A distinct square root of time behaviour of the injection pressure and the pressure response in a sandstone layer confining the fracture at the top indicate that there is vertical linear flow in the fracture rather than radial or bilinear flow. Linear fracture flow was commonly observed for large selfpropped hydraulic fractures in HDR/EGS-projects in granite also in cases where the fractures were oblique to the boreholes. It was explained by the assumption of long and highly conductive flow channels within the fractures that serve as starting line for fracture linear or bilinear flow [24]. In the present case a highly conductive fracture channel is assumed in the Detfurth and Solling sandstone. Its formation is explained by a turn from tensile to shear mode fracture propagation at the sandstone/claystone boundaries.

The pressure records could well be fitted with an analytical 1D-model that was developed during the study. This model simulates vertical linear fluid flow in a fracture confined at the bottom and the top by permeable rock layers.

Fitting of the measured pressure records with this model delivered a fracture transmissivity in the range of $2 \cdot 10^{-14} \mathrm{~m}^{3}$ to $4 \cdot 10^{-14} \mathrm{~m}^{3}$ (20 to $40 \mathrm{md} \cdot \mathrm{m}$ ) depending on assumed fracture length. This corresponds with a fracture aperture of less than $0.1 \mathrm{~mm}$. A comparison with hydraulic fractures in granite at various HDR/EGS sites show that the transmissivity of selfpropped fractures in granite are by more than a factor of 10 higher than that of the studied self-propped fracture in claystone. The transmissivity of the latter in turn is by a factor of more than 10 higher than the transmissivity of propped fractures in various shale gas formations in the US. This indicates that it is not recommended to apply the complex and publicly criticized frac-technology of the shale gas industry for 


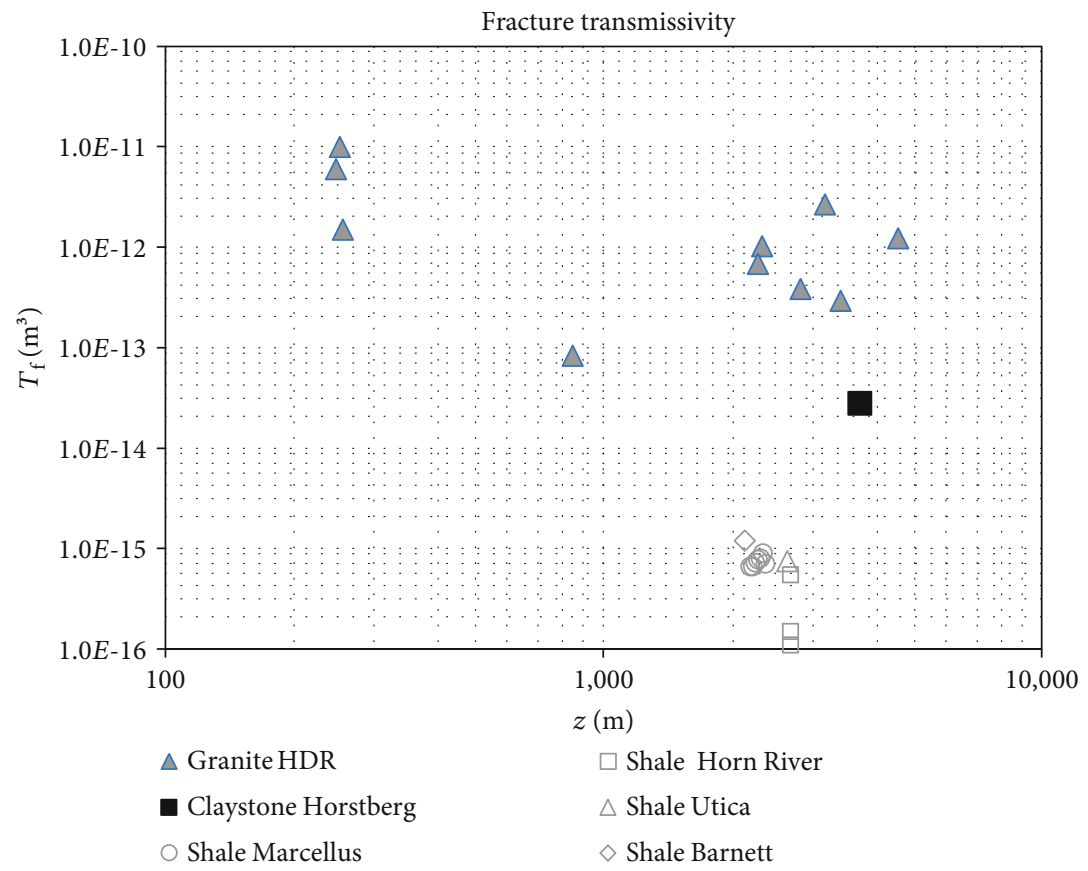

FIGURE 9: Values of fracture transmissivity vs. depth of self-propped fractures in granite and claystone and of propped fractures in shale gas reservoirs in the USA.

HDR/EGS-geothermal systems in sedimentary or crystalline rock. It should rather be considered to test the proppantfree frac-technique in shale gas reservoirs.

The storage coefficients of $4.4 \cdot 10^{-10} \mathrm{~m} / \mathrm{Pa}<\mathrm{S}_{\mathrm{f}}<2.6 \cdot 10^{-9} \mathrm{~m} / \mathrm{Pa}$ determined with the fitting procedure are amazingly high. It can hardly be explained "Bed of Nail" type fracture models. A "Zig-Zag" fracture model resulting from a multiple change of the fracture propagation mode in the layered formation may be an option (see Figure 9). This model would also explain the hypothesized formation of a highly conductive flow channel in the Detfurth sandstone.

The injectivity index of the studied fracture would allow to circulate hot water at flow rates up to about $5 \cdot 10^{-3} \mathrm{~m}^{3} / \mathrm{s}$ at a pressure difference of 50 bar between fracture inlet and outlet. This corresponds to a thermal power output of about $2 \mathrm{MW}$ for a formation temperature of $150^{\circ} \mathrm{C}$. The one-well concept developed in the GeneSys project might therefore be a solution for small to medium size building complexes. For bigger industrial applications it is recommended to create self-propped multi-fracture systems in long horizontal borehole sections with the drilling and completion technology of the shale gas industry. The high temperature in geothermal reservoirs, the extreme fracture size, and the need to intersect the fractures with a second borehole is a technical and economical challenge. The results of our study show that fractures of sufficient size and transmissivity for such concepts can be created in low permeable sedimentary rock formations like claystone by using a proppant-free frac-technology.

The large hydraulic fractures needed for EGS/HDRgeothermal reservoirs will in many cases connect to permeable features like sandstone layers, fracture zones and faults. This may happen intentionally or accidentally. For these cases our analytical method could become a useful and easy to handle tool for a quick test evaluation in the field.

The results obtained in borehole Horstberg $\mathrm{Z} 1$ are promising. But further field experiments with self-propped fractures in various rock types are necessary to confirm these findings.

\section{Data Availability}

The pressure time records of the injection test on the self-propped fracture in borehole Horstberg Z1analyzed in this study are available from co-author T. Tischner, BGR, Hanover upon request.

\section{Conflicts of Interest}

The authors declare that there is no conflict of interest regarding the publication of this paper.

\section{Funding}

Part of this study and publication of this article has received funding from the European Union's Horizon 2020 research and innovation programme under grant agreement $\mathrm{N}$. [640979] and from the Federal Ministry of Economic Affairs and Energy (BMWi) under grant agreement N. 0325946 (Horstberg).

\section{Acknowledgments}

We thank Prof. Mark D. Zoback, Stanford University and Prof. David Yoxtheimer, Penn State Marcellus Center for Outreach and Research for their help to find transmissivity 
field data of shale gas fractures and gas production records from Marcellus shale gas wells.

\section{References}

[1] J. Orzol, R. Jatho, R. Jung, P. Kehrer, and T. Tischner, “The GeneSys project - development of concepts for the extraction of heat from tight sedimentary rocks," Zeitschrift für Angewandte Geologie, vol. 2, pp. 17-23, 2004.

[2] R. Jung, "EGS - goodbye or back to the future," in Effective and Sustainable Hydraulic Fracturingpp. 95-121, InTech.

[3] MIT, The future of geothermal energy - Inpact of Enhanced Geothermal systems (EGS) on the United States in the 21st century, Idaho Nat. Lab., Idaho US, 2006.

[4] R. Jung, T. Tischner, R. Jatho, and P. Kehrer, "The Geothermal Project GeneSys - Results of massive waterfrac-tests in the Bunter sandstone formation in the Northern German Basin," in Proceedings, 30th Stanford University Workshop on Geothermal Reservoir Engineering, Stanford, CA, USA, January 2005.

[5] http://www.fracrisk.eu.

[6] T. Tischner, R. Jatho, and F. Binot, "Die Bohrung Horstberg," in Geologisches Jahrbuch, A 162, J. P. Gerling, T. Tischner, M. Kosinowski, and V. Bräuer, Eds., p. 23, Federal Institute of Geosciences and Natural Resources (BGR), Hannover, Germany, 2015.

[7] T. Röckel and C. Lempp, "Der Spannungszustand im Norddeutschen Becken," Erdöl, Erdgas, vol. 119, no. 2, pp. 73-80, 2003.

[8] T. Tischner and A. Hesshaus, "Stimulationsmaßnahmen, hydraulische Tests und geochemische Untersuchungen," in Geologisches Jahrbuch, A 162, J. P. Gerling, T. Tischner, M. Kosinowski, and V. Bräuer, Eds., Federal Institute of Geosciences and Natural Resources (BGR), Hannover, Germany, 2015.

[9] S. Wessling, T. Backers, R. Junker, and T. Tischner, Stress determination and associated analysis from pressure records during the Detfurth hydraulic stimulation (Horstberg Z1, 2003), Report, Leibniz Institute for Applied Geophysics, Arch. No. 0127547, Hanover, 2008.

[10] J. Orzol, G. R. Jung, R. Jatho, and P. Kehrer, "Extraction of geothermal heat from tight sediments," in Proceedings World Geothermal Congress 2005, Antalya, Türkei, April 2005.

[11] A. Ghassemi, A. Nygren, and A. Cheng, "Effects of heat extraction on fracture aperture: A poro-thermoelastic analysis," Geothermics, vol. 37, pp. 525-539, 2008.

[12] S. Salimzadeh, A. Paluszny, H. M. Nick, and R. W. Zimmerman, "A three-dimensional coupled thermo-hydro-mechanical model for deformable fractured geothermal systems," Geothermics, vol. 71, pp. 212-224, 2018.

[13] V. A. Torrealba, Z. T. Karpyn, H. Yoon, K. A. Klise, and D. Crandall, "Pore-scale investigation on stress-dependent characteristics of granular packs and the impact of pore deformation on fluid distribution," Geofluids, vol. 16, 207 pages, 2016.

[14] H. W. Carslaw and J. C. Jaeger, Conduction of Heat in Solids, Second Edition, Oxford University Press, 1986.

[15] C. J. Diaz, "A method of recursive images to solve transient heat diffusion in multilayer materials," International Journal of Heat and Mass Transfer, vol. 85, pp. 1075-1083, 2015.
[16] R. Jung, "Application and potential of hydraulic-fracturing for geothermal energy production," Expanded Journal Title is: Swiss Bulletin for Applied Geology, vol. 19/2, 2014.

[17] M. J. Mayerhofer, M. F. Richardson, R. N. Walker, D. N. Meehan, M. W. Oehler, and R. R. Browning, "Proppants? We don't need no proppants," in SPE Annual Technical Conference and Exhibition, San Antonino, TX, USA, October 1997.

[18] N. Walker, J. L. Hunter, A. C. Brake, P. A. Fagin, and N. Steinsberger, "Proppants? We still don't need no proppants - A perspective of several operators," in SPE Annual Technical Conference and Exhibition, pp. 27-30, New Orleans, LA, USA, September 1998.

[19] P. Mathis, G. Bierley, K. Sickles, and D. Nelson, "Water-fracs provide cost-effective well-stimulation alternative in San Joachim Valley," in SPE/AAPG Western Regional Meeting, pp. 19-23, Long Beach, CA, USA, June 2000.

[20] C. Ehlig-Economides, I. Ahmed, S. Apiwathanasorn et al., "Stimulated shale volume characterization: Multiwell case study from the Horn River shale: II. Flow perspective," in SPE-159546, SPE Annual Technical Conference and Exhibition, San Antonio, TX, USA, October 2012.

[21] M. J. Mayerhofer, E. P. Lolon, J. E. Youngblood, and J. R. Heinze, "Production Modelling in the Barnett Shale," in SPE102103, SPE Annual Technical Conference and Exhibition, pp. 24-27, San Antonio, TX, USA, September 2006.

[22] C. Cipolla, C. Gilbert, A. Sharma, and J. LeBas, "Case history of completion optimization in the Utica," in SPE Hydraulic Fracturing Technology Conference and Exhibition, The Woodlands, TX, USA, January 2018.

[23] R. Jung, Empirical Comparative Study on the Characteristics of Propped and Un-Propped Hydraulic Fractures in Shale Gas Formations, Report FracRisk project, 2017.

[24] R. Jung and R. Weidler, "A Conceptual Model for the Stimulation of the HDR-System at Soultz," Transactions - Geothermal Resources Council, vol. 24, pp. 143-147, 2000. 

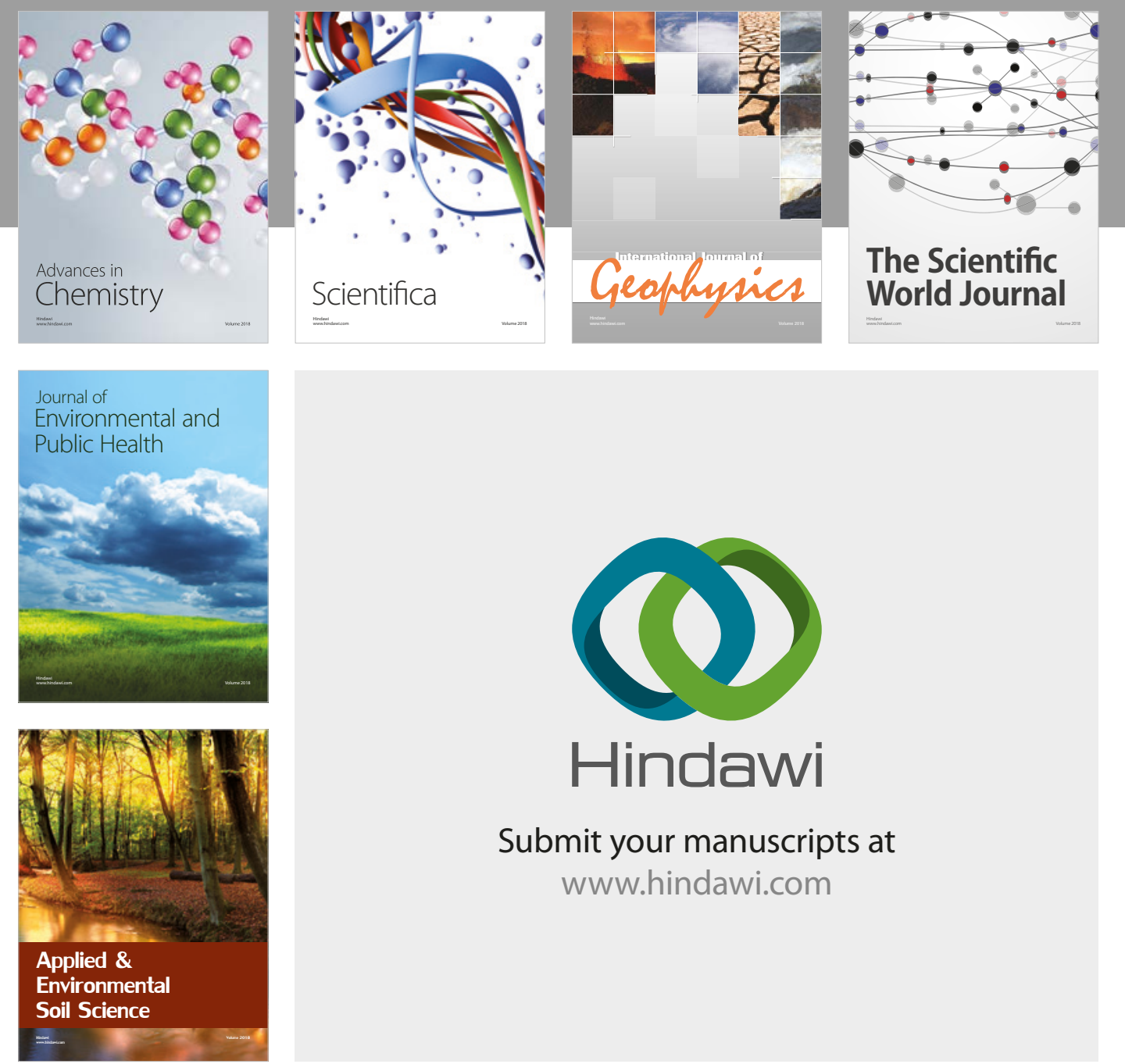

The Scientific

\section{World Journal}
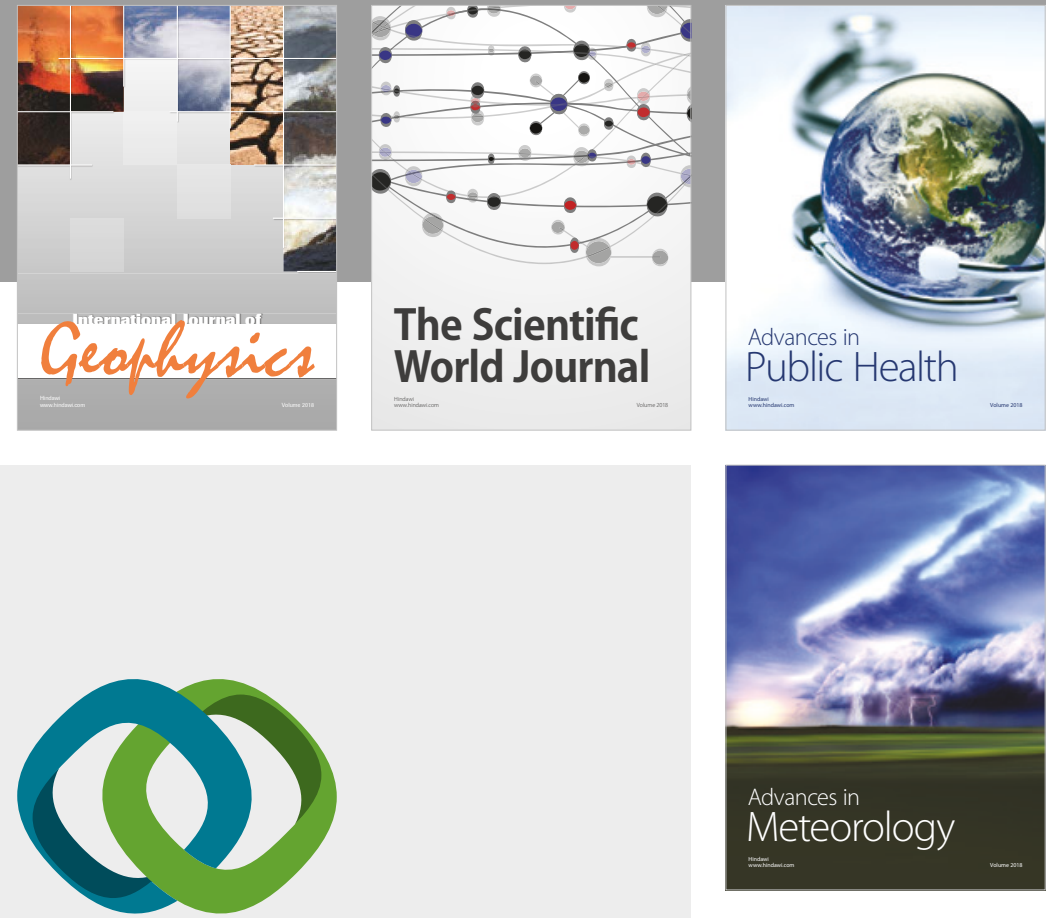

Advan

Public Health

\section{Hindawi}

Submit your manuscripts at

www.hindawi.com
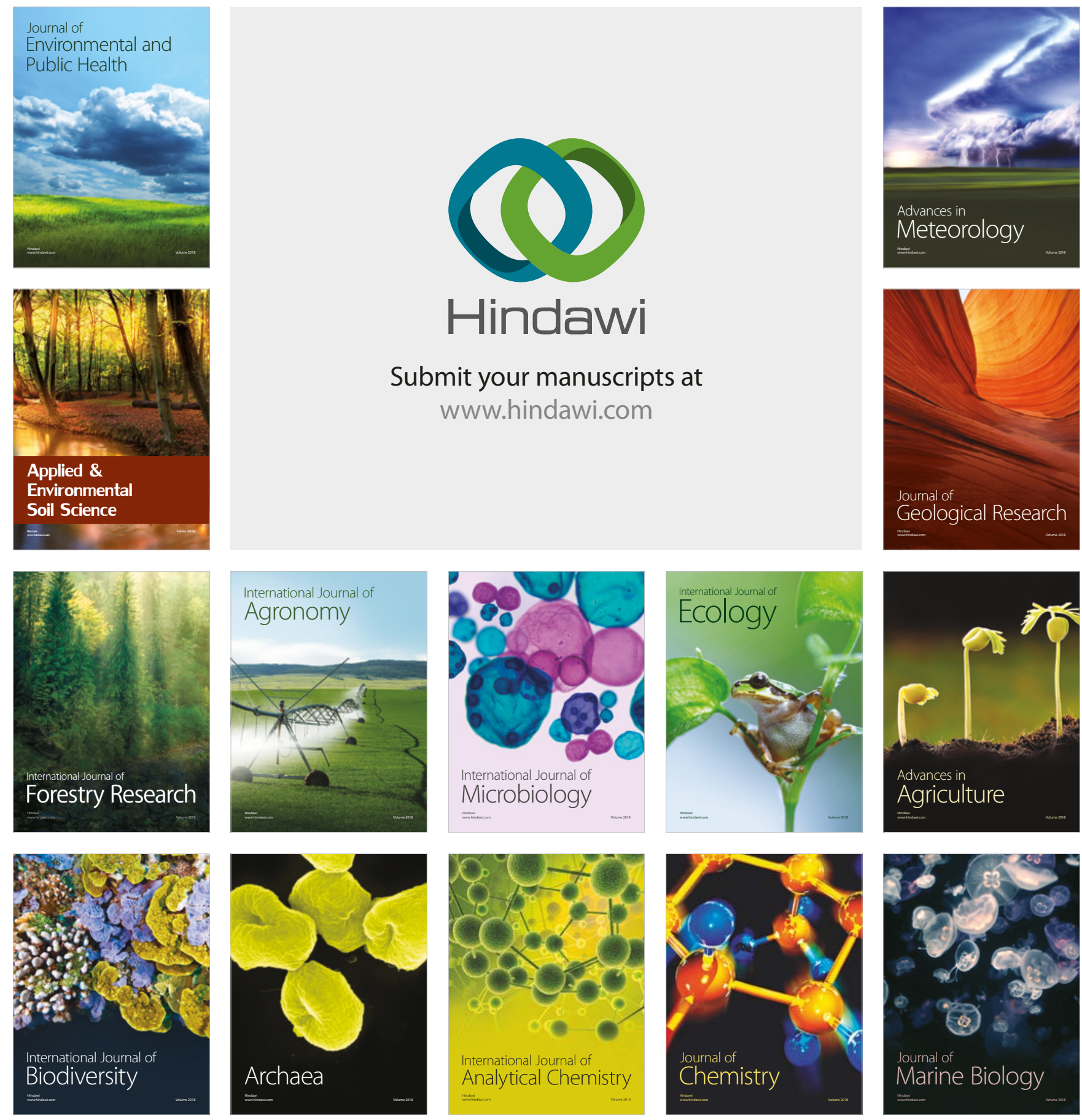